\title{
Nanoparticles in cigarette smoke; real-time undiluted measurements by a scanning mobility particle sizer
}

\author{
Wouter D. van Dijk • Simone Gopal • \\ Paul T. J. Scheepers
}

Received: 4 November 2010 /Revised: 13 January 2011 / Accepted: 18 January 2011 /Published online: 10 February 2011

(C) The Author(s) 2011. This article is published with open access at Springerlink.com

\begin{abstract}
Cigarette smoke is a complex mixture of smoke constituents, often characterised by size-resolved particle distributions. Since descriptions of ultrafine particles $<50 \mathrm{~nm}$ are absent, our aim was to explore the existence of these nanoparticles in fresh and undiluted cigarette smoke. We measured undiluted smoke particles real-time by a scanning mobility particle sizer with Faraday cup electrometer, integrated in our custom-made smoking machine. Cigarettes were smoked by $2 \mathrm{~s}$ puffs, $30 \mathrm{~s}$ puff intervals and $50 \mathrm{ml}$ puff volume. We tested six different cigarettes $(1-10 \mathrm{mg}$ tar per cigarette) at ten particle size-ranges between 6 and $50 \mathrm{~nm}$, and repeated measurements five times. The formation of nanoparticles in fresh cigarette smoke was observed over the entire range between 6 and $50 \mathrm{~nm}$, and reproduced in all cigarettes. The highest mean yield was $8.8 \times 10^{9}\left(\mathrm{SD}=1.1 \times 10^{9}\right)$ particles per cigarette at the largest particle size range by high-tar cigarettes. Nanoparticle counts appear to increase with particle size, claimed tar values and blocking of filter ventilation holes, and inversely with butt length. Fresh undiluted cigarette smoke contains large amounts of potentially toxic nanoparticles $<50 \mathrm{~nm}$. We recommend to further study nanoparticles in the characterisation of cigarette smoke.
\end{abstract}

W. D. van Dijk $(\bowtie) \cdot$ S. Gopal

Department of Primary and Community Care,

Radboud University Nijmegen Medical Centre,

Internal postal code 117, P.O. Box 9101, 6500 HB Nijmegen,

The Netherlands

e-mail: w.vandijk@aios.umcn.nl

P. T. J. Scheepers

Department of Epidemiology, Biostatistics and HTA,

Radboud University Nijmegen Medical Centre,

Internal postal code 117, P.O. Box 9101, 6500 HB Nijmegen,

The Netherlands
Keywords Nanoparticles · Cigarette smoke $\cdot$ SMPS+E Particle size distribution

\section{Introduction}

Cigarette smoke is a complex mixture of potentially pathogenic smoke constituents, including particulate matter, volatile substances and gasses. Several techniques that characterise cigarette smoke have been reviewed during the last century, including the current method to categorise cigarettes by tar, nicotine and carbon monoxide content $[1$, $2,3]$. Techniques that analyse smoke constituents more specifically and usually in relation to tar yields include single constituent analyses [1, 4, 5, 6, 7] and size-resolved particle distributions by different spectrometry methods $[8$, 9, 10, 11, 12].

Limitations of measurement techniques include low time resolution, aerosol (ageing) dynamics and high particle concentrations, which cause the need for (possibly timedelaying) dilution $[1,8]$. Particles consequently agglomerate substantially before measurement, apart from evaporation, condensation, diffusion and (gravitational) sedimentation [1]. Mainly due to these limiting measurement factors, until recently, only two reports have been published of smoke particles below $100 \mathrm{~nm}$ in diameter $[9,10]$. The first used orifices of $0.5 \mathrm{~mm}$ whereas the other needed a dilution of 80,000:1, which are both important limitations. Recently, nanoparticles have been studied more extensively by realtime size-resolved particle distributions for instance by electrical low-pressure impactor and differential electrical mobility particle spectrometry $[8,12,13,14]$. These techniques are able to measure particles down to $5 \mathrm{~nm}$. Both techniques however implicated dilutions of 50:1 and 750:1 and time delays range from $0.2 \mathrm{~s}$ to $1.5 \mathrm{~s}$. Furthermore, the 
related studies only report the count median diameter and do not explicitly study nanoparticles. Some figures however do reveal the existence of nanoparticles upward of $70 \mathrm{~nm}[8$, 12]. Still, little is known about particles smaller than $70 \mathrm{~nm}$. Nanoparticles either are very difficult to measure with the available techniques or are only scarce. As particles are abundant above $100 \mathrm{~nm}$ and as the largest amount of cigarette smoke has been reported to result from gasses with diameters of around $0.5 \mathrm{~nm}$ [1], one might consequently expect large quantities of particles within the size-range between 1 and $100 \mathrm{~nm}$. The existence of nanoparticles in cigarette smoke would be quite relevant as they likely have a higher deposition and transposition and thus a higher toxic potency $[15,16]$.

We hypothesise the existence of large quantities of nanoparticles above $5 \mathrm{~nm}$. The Scanning Mobility Particle Sizer with Faraday Cup Electrometer (SMPS+E), by Grimm Aerosol Technik, measures concentrations up to $10^{8}$ particles per $\mathrm{cm}^{3}$ and is able to detect nanoparticles from 6 to $1,100 \mathrm{~nm}$ real-time. SMPS +E measurements are based on size-specific electrical loading of particles and subsequently size-specific electrical and mechanical mobility of particles. The SMPS $+\mathrm{E}$ appears to have promising qualities in this, so far, poorly explored particle size range within cigarette smoke.

Our aim in this study is to explore this existence of nanoparticles in fresh unaged and undiluted cigarette smoke, and to determine their contribution to human cigarette smoke exposure, i.e., their contribution to human health-hazard. Since filter ventilation is a very important factor in altering (particle size-resolved) smoke yields, $[8$, $12,17]$ by dilution and by altering combustion, we also explored the influence of filter ventilation on the appearance of nanoparticles.

\section{Methods}

Study design The main levels that influence smoke measurements include production, collection and measurement itself. We standardised smoke production by a custommade smoking machine, integrated in our SMPS $+\mathrm{E}$ (Fig. 1), which consequently standardised the smoke collection and allowed standardisation of the measurements. By a pilot study (not reported), we adjusted the smoking regime and measurement settings so we ended up with a standardised method that produced typical and valid smoking interval-dependent particle counts [12]. We selected a 2 -s puff, 30 -s interval, $50-\mathrm{ml}$ puff volume, and ten continuous $8-\mathrm{Hz}$ single channel measurements, with geometric mean particle diameters between 5.65 and $50.38 \mathrm{~nm}$ at 5-nm intervals. Each channel covers a size range of approximately $1 \mathrm{~nm}$. We measured six cigarettes with

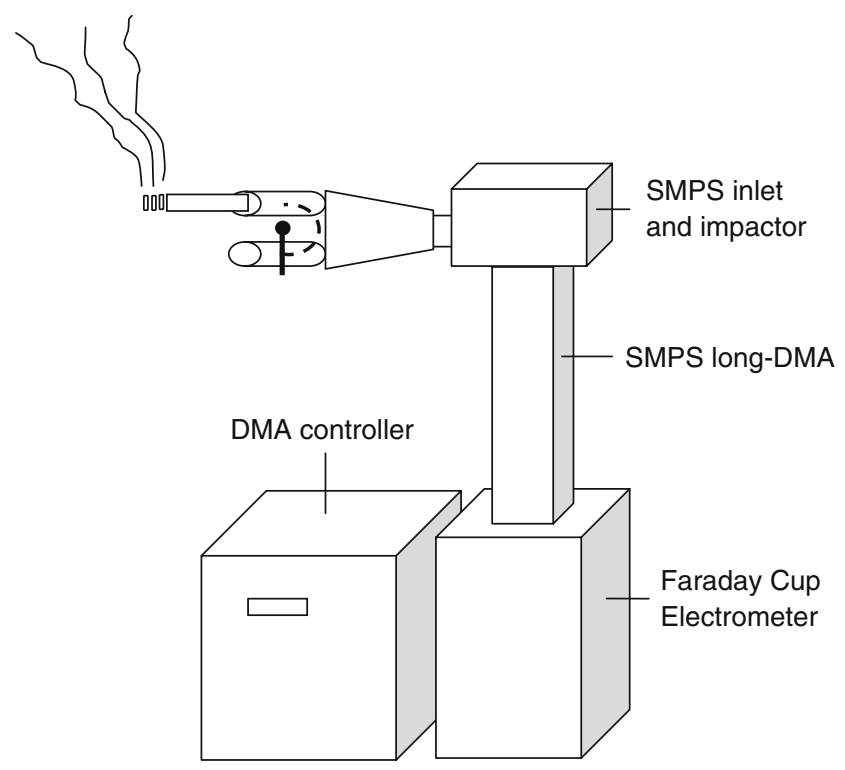

Fig. 1 Schematic test formation. The valve inlets are connected to a cigarette and to clean room air. A timer controls the valve inlets. The DMA controller ensures a continuous flow of $1.5 \mathrm{l} / \mathrm{min}$. DMA: differential mobility analyzer. Connections are by carbosilicon tubing

different filter ventilation capacities and different determined tar mass yields, and each cigarette measurement was repeated five times: three cigarettes manufactured by Phillip Morris and three by British American Tobacco as displayed in Table 1.

Smoke production Smoking was based on the constant airflow of the spectrometer, which was connected to the 4-mm valve outlet by inert carbosilicon tubing. The setting included a two-way valve with two 4-mm inlet orifices that allowed smoking through the orifice with the cigarette attached and allowed a smoking interval through the other orifice with clean room air attached. A timer that managed the valve direction could subsequently adjust puff duration and frequency. We ignited cigarettes electrically and

Table 1 Cigarette brands, from Dutch markets, used for smoke measurements, categorised by their tar, nicotine and $\mathrm{CO}$ amount

\begin{tabular}{llll}
\hline Cigarette brand & Tar (mg) & Nicotine (mg) & CO (mg) \\
\hline Phillip Morris & & & \\
Marlboro Red & 10 & 0.8 & 10 \\
Marlboro Flavour plus & 6 & 0.4 & 8 \\
Philip Morris One & 1 & 0.1 & 2 \\
British American Tobacco & & & \\
Kent Futura & 8 & 0.7 & 10 \\
Kent original taste & 4 & 0.4 & 5 \\
Kent Infina & 1 & 0.1 & 2 \\
\hline
\end{tabular}


smoked cigarettes up to $32 \mathrm{~mm}$ from the filter end. All cigarettes were smoked with their filters inserted $2 \mathrm{~cm}$ in the filter holder. The three cigarettes manufactured by Phillip Morris were also smoked with their filters inserted $1 \mathrm{~cm}$ and their main filter ventilation holes uncovered. Cigarettes were stored beforehand at $22{ }^{\circ} \mathrm{C}$ and at $60 \%$ relative humidity for at least 2 days.

Study outcome We defined the size-resolved particle distribution per smoked cigarette as our outcome. Particle distributions are presented as lognormal size distributions: $\mathrm{d} N / \mathrm{d} \ln (D)$ per ml produced smoke- $\mathrm{d} N$ equals particle count, $\operatorname{d} \ln (D)$ equals lognormal channel size range [18]. For each channel, the total particle count of one cigarette measurement was derived from area under the curve calculations from all successive $2 \mathrm{~s}$ puff periods. We multiplied the mean particle concentration per puff by 50 , to attain the particle number per $50-\mathrm{ml}$ puff volume. We calculated the mean total particle count of five different measurements.

Analysis We analysed mean channel particle counts, including standard deviation (SD) and coefficients of variation. Test of normality for distributions was performed by Shapiro-Wilk $(p<0.05)$ [19]. We compared particle counts of different cigarette types and filter ventilation blocking conditions, and performed analysis of variance (ANOVA) for each separate channel. We used SPSS 16.0 for all analyses.

\section{Results}

Filters inserted $2 \mathrm{~cm}$ By evaluating the interval-dependent particle counts, we observed valid smoke peaks lasting $1 / 8$ to $2 \mathrm{~s}$ at all channels for all six cigarettes. However, at 46 and $50 \mathrm{~nm}$, some puffs attained the maximum concentration measurable, particularly in high-tar cigarettes. Particle counts per puff were higher at smaller butt lengths, due to an increase of both the peak height and duration (Fig. 2). Coefficients of variation of total particle counts per cigarette ranged from $5 \%$ to $92 \%$ (mean $22 \%$ ) for different channels. Tests of normality revealed four non-parametric distributions out of 60 tests.

For cigarettes manufactured by Phillip Morris, the lowest particle yield was at $6 \mathrm{~nm}$ by Philip Morris One, $2.6 \times 10^{6}\left(\mathrm{SD} 1.2 \times 10^{6}\right)$ particles per cigarette, whereas the highest yield was at $50 \mathrm{~nm}$ by Marlboro Red, $8.8 \times 10^{9}$ $\left(\mathrm{SD}=1.1 \times 10^{9}\right)$ particles per cigarette. We observed that particle counts increased parallel to particle diameter size similarly across different cigarette types (Fig. 3). Although particle counts differed significantly between different

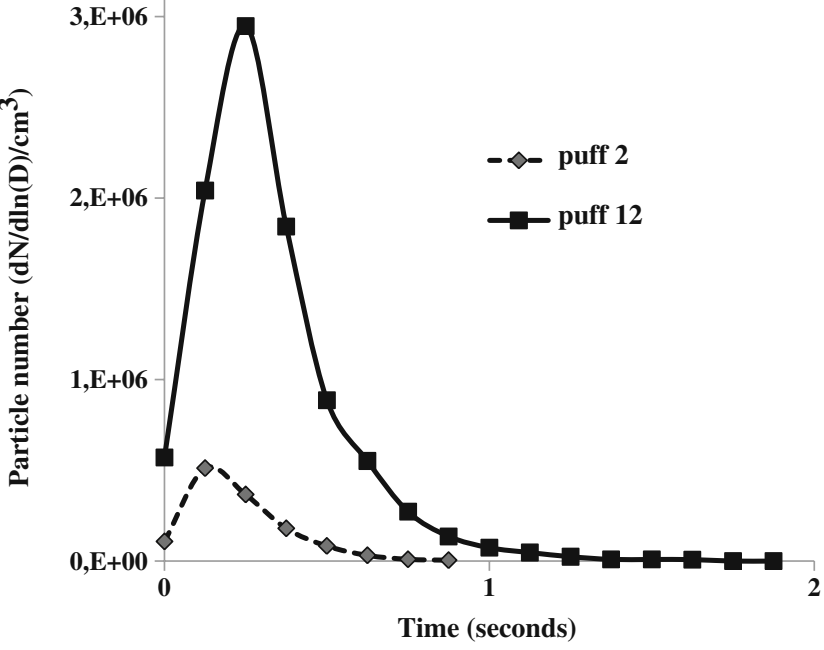

Fig. 2 An example of time-dependent particle numbers within a puff, measured for Marlboro Red, at $41 \mathrm{~nm}$ by two different puffs

cigarette types (Table 2), they did not differ much below $40 \mathrm{~nm}$, whereas above $40 \mathrm{~nm}$ the highest tar cigarette revealed excessive particle yields due to a very rapid increase.

We observed the lowest particle yield in Kent cigarettes at $6 \mathrm{~nm}$ by Kent Infina, $3.0 \times 10^{6}\left(\mathrm{SD} 9.4 \times 10^{5}\right)$ particles per cigarette, and the highest yield at $50 \mathrm{~nm}$ by Kent Futura, $5.8 \times 10^{9}\left(\mathrm{SD} 1.3 \times 10^{9}\right)$ particles per cigarette (Fig. 4). Again, particle yields increased similarly along with particle diameter size across the different cigarettes, with highest yields for the highest tar cigarette (Kent Futura), significant at most channels. However, differences were relatively small compared to claimed tar mass yields.

Filters inserted $1 \mathrm{~cm}$ Three cigarettes were also tested with unblocked filter ventilation holes as well. For these

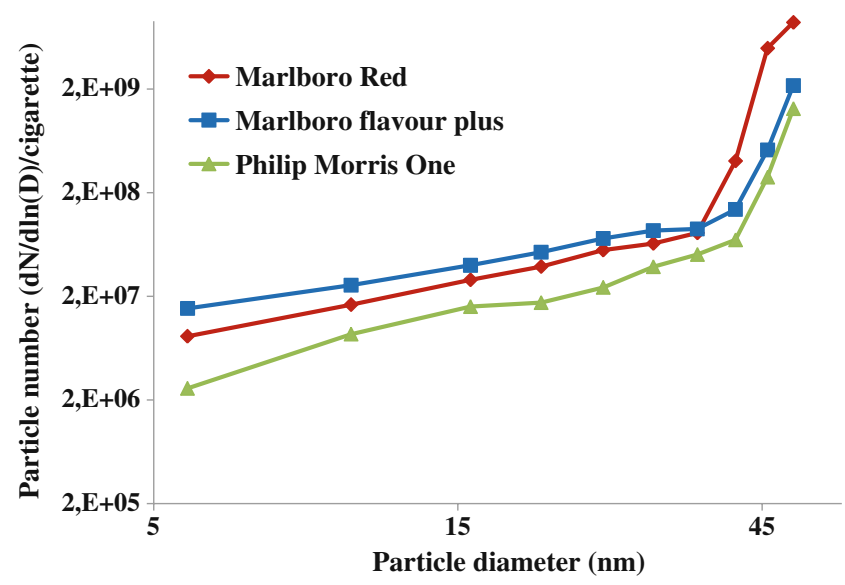

Fig. 3 Size-resolved particle distribution of cigarettes manufactured by Philip Morris, smoked with $2 \mathrm{~cm}$ filter insertion at 2-s puffs, $30-\mathrm{s}$ intervals and 50-ml puff volume 
Table 2 Analysis of variance (multiple comparisons by Least Significant Difference test, homogeneity of variance assumed) between different cigarette types for ten different channels ranging between 6 and $50 \mathrm{~nm}$, based on 5 different measurements

\begin{tabular}{|c|c|c|c|c|c|c|c|c|c|c|}
\hline & $6 \mathrm{~nm}$ & $10 \mathrm{~nm}$ & $15 \mathrm{~nm}$ & $20 \mathrm{~nm}$ & $25 \mathrm{~nm}$ & $30 \mathrm{~nm}$ & $36 \mathrm{~nm}$ & $41 \mathrm{~nm}$ & $46 \mathrm{~nm}$ & $50 \mathrm{~nm}$ \\
\hline \multicolumn{11}{|l|}{ Filter inserted $2 \mathrm{~cm}$} \\
\hline Marlboro & 0.00 & 0.00 & 0.00 & 0.01 & 0.00 & 0.00 & 0.28 & 0.09 & 0.01 & 0.00 \\
\hline Marlboro Flavour Plus & $-^{\mathrm{a}}$ & $-^{\mathrm{a}}$ & $-^{\mathrm{a}}$ & $--^{a, b}$ & $-^{\mathrm{a}}$ & $-^{\mathrm{a}}$ & $-^{\mathrm{a}}$ & $-{ }^{a}, \mathrm{~b}$ & $-{ }^{\mathrm{a}, \mathrm{b}}$ & $-^{\mathrm{a}}$ \\
\hline Philip Morris One & 0.00 & 0.00 & 0.00 & 0.00 & 0.00 & 0.00 & 0.00 & 0.05 & 0.32 & 0.13 \\
\hline Kent futura & 0.00 & 0.01 & 0.03 & 0.20 & 0.00 & 0.00 & 0.01 & 0.17 & 0.00 & 0.00 \\
\hline Kent original taste & $-^{\mathrm{a}}$ & $-^{\mathrm{a}}$ & $-^{\mathrm{a}}$ & $-^{\mathrm{a}}$ & $-^{\mathrm{a}}$ & $-^{\mathrm{a}}$ & $-^{\mathrm{a}}$ & $-^{\mathrm{a}}$ & $-^{\mathrm{a}}$ & $-^{\mathrm{a}}$ \\
\hline Kent infina & 0.00 & 0.03 & 0.78 & 0.01 & 0.27 & 0.08 & 0.11 & 0.85 & 0.79 & 1.00 \\
\hline \multicolumn{11}{|l|}{ Filter inserted $1 \mathrm{~cm}$} \\
\hline Marlboro & 0.05 & 0.46 & 0.54 & 0.79 & 0.22 & 0.00 & 0.03 & 0.04 & 0.42 & 0.11 \\
\hline Marlboro Flavour Plus & $-\mathrm{a}, \mathrm{b}$ & $--^{a}, \mathrm{~b}$ & $--^{\mathrm{a}, \mathrm{b}}$ & $-{ }^{\mathrm{a}, \mathrm{b}}$ & $--^{a, b}$ & $-^{\mathrm{a}}$ & $-{ }^{\mathrm{a}, \mathrm{b}}$ & $-^{\mathrm{a}}$ & $-{ }^{\mathrm{a}, \mathrm{b}}$ & $-{ }^{\mathrm{a}, \mathrm{b}}$ \\
\hline Philip Morris One & 0.76 & 0.36 & 0.46 & 0.53 & 0.58 & 0.52 & 0.12 & 0.04 & 0.08 & 0.00 \\
\hline
\end{tabular}

${ }^{\mathrm{a}} p$ values for difference with redundant variable

${ }^{\mathrm{b}}$ Homogeneity of variance not assumed (multiple comparisons by Games-Howell)

cigarettes, we observed valid smoke peaks only at particle sizes upward of $30 \mathrm{~nm}$, based on the shapes and height of the smoke peaks, peak intervals, and the standard deviations of the particle counts per cigarette. Figure 5 shows an example of particle numbers measured at $41 \mathrm{~nm}$. Below $30 \mathrm{~nm}$, these peaks appeared scarce and with random intervals, and relatively large standard deviations. Between 30 and $50 \mathrm{~nm}$ coefficients of variation ranged from $9 \%$ to $101 \%$ (mean $49 \%$ ). Tests of normality revealed two nonparametric distributions out of 15 tests. Particle counts per puff again were higher at smaller butt lengths, increased along with particle diameter size, and appeared to be reflected by claimed tar mass yields (Fig. 6). Compared to smoking with blocked filter ventilation holes, the yields of all cigarettes tended to decrease about tenfold at each channel, but mainly affected Philip Morris One cigarettes with high filer ventilation capacity.

\section{Discussion}

Although previous studies on cigarette smoke did not explicitly report on nanoparticles between 6 and $50 \mathrm{~nm}$, our study reveals their existence in fresh and undiluted smoke, from cigarettes smoked by 2 -s puffs, 30 -s intervals and $50-\mathrm{ml}$ puff volumes. We managed to reproduce the results in different cigarette types and by different filter ventilation

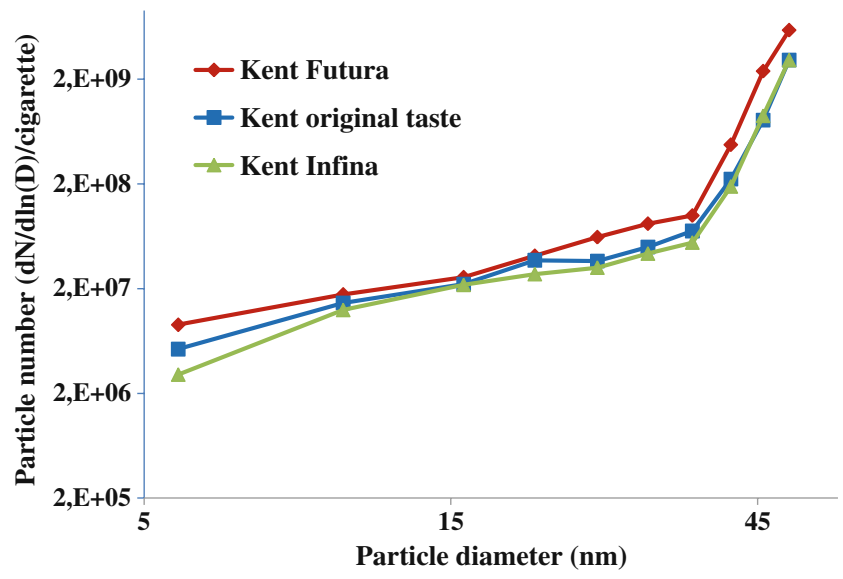

Fig. 4 Size-resolved particle distribution of cigarettes manufactured by British American Tobacco, inserted $2 \mathrm{~cm}$ and smoked at 2-s puffs, 30 -s intervals and 50-ml puff volume

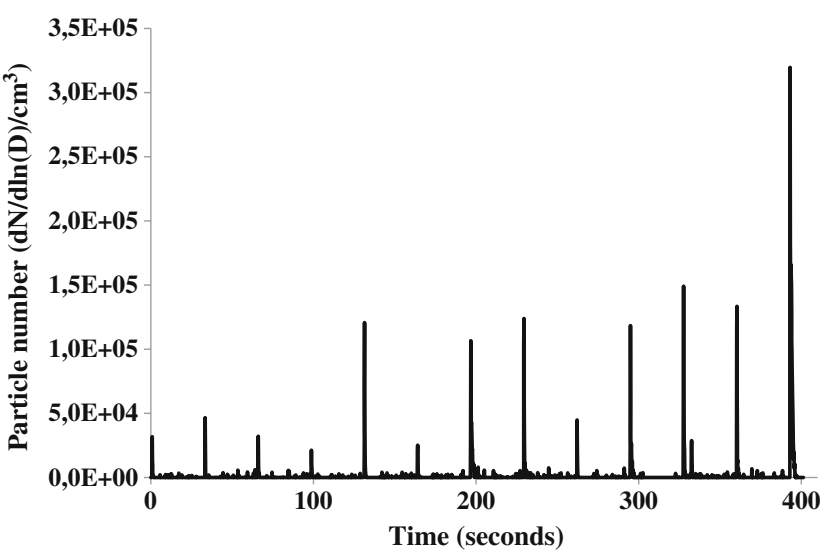

Fig. 5 Example of smoking interval-dependent particle numbers for Marlboro Flavour plus, measured at $41 \mathrm{~nm}$, for 13 successive puffs. Smoke was produced by 2 -s puffs, 30 -s intervals, $50-\mathrm{ml}$ puff volume and filter insertion of $1 \mathrm{~cm}$ 


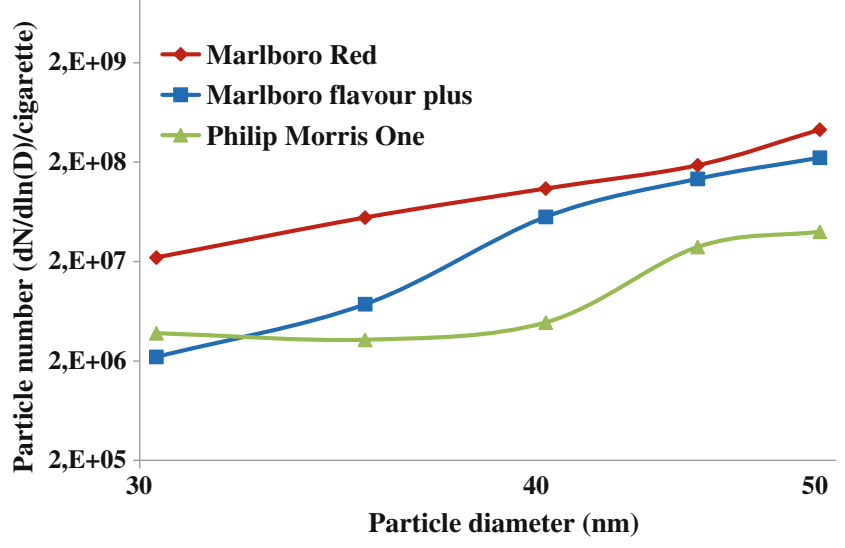

Fig. 6 Size-resolved particle distribution of cigarettes manufactured by Philip Morris, smoked with $1 \mathrm{~cm}$ filter insertion at 2-s puffs, 30-s intervals and 50-ml puff volume

blocking. For a single channel measurement, the highest mean yield was $8.8 \times 10^{9}\left(\mathrm{SD}=1.1 \times 10^{9}\right)$ particles per cigarette.

Nanoparticle counts appear to increase with particle size, claimed tar values and blocking of filter ventilation holes, and inversely with butt length. Although high-tar cigarettes seem to have an overall excess of particles compared to lower tar cigarettes, the channel-based ratios between the particle yields vary.

Validation Variation of size-dependent particle counts within a certain cigarette appear comparable to the variations of tar measurements within a certain cigarette. Apparently, most of our observed variation is due to natural variations within the cigarettes themselves. In addition, our results revealed smoking interval-dependent particle counts, and the increase of particle counts for successive puffs corresponds to the results of prior studies [11,8]. Alas, at two channels - 46 and $50 \mathrm{~nm}$-we sometimes attained the concentration threshold, particularly in high-tar cigarettes. Furthermore, in our pilot study, we observed a lower limit of necessary smoking intensity that suggests nanoparticles require combustion circumstances that not necessarily always occur during real-life smoking. Altogether, we believe our method is valid in measuring fresh and undiluted cigarette smoke, though the two largest channels might underestimate the particle counts in high-tar cigarettes.

Interpretation Although the interpretation of our results appears confined to our smoking regime and selection of cigarettes, the possibility to generalise our results is tempting. Since our smoking regime is moderate compared to other common used regimes [1] and our selection of cigarettes cover a wide range of cigarette types, we assume some general remarks on our results may be allowed.
Although we hypothesised high particle counts, compared to previous studies that report size-resolved particle distributions in fresh cigarette smoke, the contribution of our encountered nanoparticles would be only a few percent [8]. Even more, the particle counts decreased for smaller particles. Possibly, the small nanoparticles have a high potency to quickly agglomerate into larger smoke constituents or to disperse into smaller molecules due to their volatile properties. In addition, the increase of nanoparticle counts due to smaller butt lengths, also suggests crucial time-dependent agglomeration and evaporation in successive puffs, apart from improved combustions and decreased tobacco-dependent filter potency, which has already been observed for larger particles [8, 12]. However, by a possibly increased deposition in and transposition through the pulmonary tissue, the probably excessive toxic properties of these nanoparticles would still indicate a substantial contribution in health-hazard $[15,16]$.

Overall, the particle yields seem to depend on claimed tar values, with higher yields for higher-tar cigarettes. Although the particle counts only roughly reflect the size resolved particle distributions, it suggests an overall enhanced combustion and increased production of all particles for higher-tar cigarettes but maybe also a different combustion with different size-resolved particle distributions.

Interpretation of (blocking of) filter ventilation holes was only possible for channels $\geq 30 \mathrm{~nm}$. However, a more intense regime by ventilation blocking seems to excessively increase nanoparticle counts in both high-ventilated and low-ventilated filters. Although an excess of particles by vent-blocking - as measured by tar yields and carbon monoxide - has already been observed particularly in high-ventilation cigarettes, [20] the production of nanoparticles is influenced substantially by low-ventilation as well. Otherwise, we might have encountered a tipping point for combustion requirements. In addition, the differences between Philip Morris One and Marlboro Red cigarettes were smaller when ventilation holes were blocked, which equalises dilution and combustion circumstances across different cigarette types. The remaining differences in particle yield however, indicate that other factors like porous cigarette papers, expanded tobacco and reconstituted tobacco sheet, have a substantial influence on nanoparticles as well. These effects seem to be more pronounced on the formation of nanoparticles than expected from their effects on tar yields [21].

In conclusion, when cigarettes are smoked by moderate smoking regimes, fresh and undiluted cigarette smoke contains an abundance of nanoparticles, which has not been described previously. These particles are present in such amounts and likely have relatively high toxic properties. Therefore, a substantial toxic effect on human health can be expected. The production of nanoparticles 
requires a minimum smoking intensity, and is related to particle size, filter ventilation holes, butt length, and claimed tar values. We suggest to further study the necessity of measuring these particles in the smoke characterisation of different cigarettes.

Open Access This article is distributed under the terms of the Creative Commons Attribution Noncommercial License which permits any noncommercial use, distribution, and reproduction in any medium, provided the original author(s) and source are credited.

\section{References}

1. Borgerding M, Klus H (2005) Exp Toxicol Pathol 57(Suppl 1):43-73

2. Philip Morris International Management SA. www.philipmorrisin ternational.com, accessed 2010

3. Baker RR (2002) Beiträge zur Tabakforschung International 20:23-41

4. Chepiga TA, Morton MJ, Murphy PA, Avalos JT, Bombick BR, Doolittle DJ, Borgerding MF, Swauger JE (2000) Food Chem Toxicol 38:949-962

5. Gendreau PL, Vitaro F (2005) Can J Public Health 96:167-172
6. Gregg E, Hill C, Hollywood M, Kearney M, McAdam K, McLaughlin D, Purkis S, and Williams M (2004) Beiträge zur Tabakforschung International/Contributions to Tobacco Research 21:117-138.

7. D. Hoffmann. Analysis of toxic smoke constituents. In: Toxicity testing plan vol. 5. 1993.

8. Adam T, McAughey J, McGrath C, Mocker C, Zimmermann R (2009) Anal Bioanal Chem 394:1193-1203

9. Ingebrethsen BJ (1986) Aerosol Sci Technol 5:423-433

10. Anderson PJ, Wilson JD, Hiller FC (1989) Am Rev Respir Dis 140:202-205

11. Bernstein DM (2004) Inhal Toxicol 16:675-689

12. Kane DB, Asgharian B, Price OT, Rostami A, Oldham MJ (2010) Inhal Toxicol 22:199-209

13. Dickens C, McGrath C, Warren N, Biggs P, McAughey J (2009) J Phys Conf Ser 151:012019

14. McGrath C, Warren N, Biggs P, McAughey J (2009) J Phys Conf Ser 151:012018

15. Jaques PA, Kim CS (2000) Inhal Toxicol 12:715-731

16. Schmid O, Möller W, Semmler-Behnke M, Ferron GA, Karg E, Lipka J, Schulz H, Kreyling WG, Stoeger T (2009) Biomarkers 14:67-73

17. Becquemin $\mathrm{MH}$, Bertholon JF, Attoui M, Roy F, Roy M, Dautzenberg B (2007) Rev Mal Respir 24:845-852

18. Reischl GP (1991) J Aerosol Sci 22:297-312

19. Shapiro SS, Wilk MB (1965) Biometrika 52:591-611

20. Kozlowski LT, O’Connor RJ (2002) Tob Control 11(Suppl 1):I40-I50

21. O'Connor RJ, Hammond D, McNeill A, King B, Kozlowski LT, Giovino GA, Cummings KM (2008) Tob Control 17(Suppl 1):i1i5 